\title{
Agnosticism as settled indecision
}

\author{
Verena Wagner ${ }^{1}$ (I)
}

\begin{abstract}
In this paper, I spell out a descriptive account of agnosticism that captures the intuitive view that a subject enters the mental state of agnosticism via an act or event called suspension. I will argue that agnosticism is a complex mental state, and that the formation of an attitude is the relevant act or event by which a subject commits to indecision regarding some matter. I will suggest a 'two-component analysis' that addresses two aspects that jointly account for the settled state of agnosticism: (1) the subject's de facto indecision and (2) the subject's commitment to her indecision. Unlike meta-cognitivist or sui generis accounts, I do not take the agnostic's commitment to indecision as constitutive for her indecision but rather as an evaluation or qualification of the indecision that she already exhibits. Agnosticism, thus, is a settled form of indecision that marks the end of inquiry.
\end{abstract}

Keywords Agnosticism - Suspension of judgment - Indecision · Non-belief . Suspended judgment

\section{Introduction}

In this paper, I am interested in what people are doing when they enter the mental state of agnosticism by an act or event called suspension. Thus, this is primarily a philosophy of mind project that aims to give a descriptive account of agnosticism. When I refer to accounts of agnosticism or suspension, what I mean are descriptive accounts or at least descriptive elements of the accounts in the literature. However, some aspects of my discussion will have consequences for the normative profile of suspension and agnosticism that I will briefly mention in Sect. 3.3.

Verena Wagner

v.wagner@uni-konstanz.de

1 Department of Philosophy, University of Constance, Fach 17, 78457 Constance, Germany 
I will restrict the discussion of suspension to inquiry-ending suspension, which I take to be the relevant act or event that leads to agnosticism. This is not to say that suspension necessarily brings inquiry to an end. There are different kinds of suspension, I think, and we can make a distinction between those that are inquiryopening and others that are inquiry-ending. It is an interesting question what makes these kinds of suspension fall under the same genus, but it is not the question that I will address in this paper. Having said that, I will say a bit more about these two kinds of suspension in general (Sect. 2.1.2) and about their respective roles for committing to indecision (Sect. 2.2.2).

The paper is divided into two parts. In the first part, I will establish six requirements that have to be met by an appropriate analysis of the agnostic's mental state. I take these requirements to be adequacy conditions that can be met in different ways by different accounts. To define these requirements, I will refer to existing accounts in the literature but will also argue for additional requirements that have not yet been addressed. In my discussion, I will also point out how different accounts in the literature meet (or do not meet) the respective requirements. I will dedicate the first group of requirements (Cognitive Contact, Proper End, Lost Reasons) to Jane Friedman, who provided us with reasons to abandon non-belief accounts for attitude accounts. The second group of requirements that I will discuss (Doxastic Neutrality, Commitment, Revision) will create problems for two popular versions of attitude accounts: the sui generis account and reductive meta-cognitive accounts. It will be central to clarify the role of non-agnostic indecision and the transition between the mental states of agnostic and non-agnostic (or 'mere') indecision.

In the second part of the paper, I will spell out my own account of agnosticism. I will argue that the relevant act of suspension that moves subjects to agnosticism is the formation of the attitude of endorsement with respect to their own indecision. The attitude of endorsement can be understood as a certain form of commitment that specifically targets mental states. Only by endorsing one's de facto or 'mere' indecision, the subject suspends inquiry in the appropriate way which leads her to the state of agnosticism. I will address the indecision and the commitment to indecision as independent components that are only structurally related. Unlike meta-cognitivist or sui generis accounts, I do not take the agnostic's commitment to indecision as constitutive for her indecision but rather as an evaluation or qualification of the indecision that she already exhibits. Agnosticism, thus, is a settled form of indecision that marks the end of inquiry.

It may be useful to compare settling one's indecision to the way two-component glue works. Because the hardener and the resin are packed in separate cartridges, the hardener does not bring about the resin, but if the two are mixed together appropriately, the resin's chemical structure is stabilised via a chemical reaction. Likewise, the subject's commitment to her own indecision does not bring about that she is undecided but only stabilises, or settles, her de facto indecision. Unfortunately, the glue metaphor is not perfect because the chemical reaction is irreversible. This is not the case for one's commitment to indecision. Agnosticism can be revised, so I will argue, either by adopting a belief or by giving up the endorsement of one's indecision. If a subject's revision is prompted by undercutting defeaters, 
she can take back the commitment to her indecision without thereby giving up her indecision altogether.

\section{Requirements for a descriptive account}

In the following, I will discuss six requirements that a descriptive account of the mental state of agnosticism has to meet: in Sect. 2.1, I attribute the first three requirements-Cognitive Contact, Proper End and Lost Reasons - to Friedman (2013b), who provided important counterexamples against non-attitude accounts of agnosticism. These requirements support the view that it is the formation of a certain attitude in virtue of which a subject suspends and thereby enters the settled state of agnosticism. In Sect. 2.2, I will introduce three further requirements that any attitude account of agnosticism has to meet: Doxastic Neutrality, Commitment, and Revision. I will discuss these requirements in the context of reductive and nonreductive attitude accounts.

\subsection{Lessons from Friedman}

\subsubsection{Cognitive Contact}

The most natural candidate for representing a subject's indecision regarding some proposition $p$ is the property of lacking any doxastic attitude regarding $p .{ }^{1}$ This privative state of non-belief must not be confused with disbelief and is defined as follows: a subject $S$ is in the state of non-belief with regard to a proposition $p$ if and only if $S$ neither believes nor disbelieves that $p$. In contrast to believing and disbelieving, non-belief is not an attitude the subject forms but is a merely privative state of the subject. ${ }^{2}$ In other words, the state of non-belief with respect to a proposition $p$ is nothing but the joint absence of a believing and a disbelieving attitude regarding $p$.

As philosophers have pointed out ${ }^{3}$, the fact that $S$ is in the state of non-belief with regard to $p$ is insufficient for $S$ being agnostic with regard to $p$, because the mere absence of doxastic attitudes regarding $p$ allows for $S$ 's not being (and never having been) cognitively in contact with $p$. Therefore, the first requirement that an account of agnosticism has to meet is Cognitive Contact:

\footnotetext{
${ }^{1}$ I treat questions as well as propositions as relevant objects for indecision and agnosticism. Friedman takes the object of her sui generis attitude of suspension to be a question rather than a proposition, as she spells out in Friedman (2013a, 2017). Even though I find Friedman's arguments convincing, I will not discuss the matter in this paper, because it is not relevant to the points I am going to make about agnosticism. Because the positions in the debate I will discuss predominantly use the propositional reading of suspension and agnosticism, I will not always add the interrogative reading.

2 I will treat 'disbelieving that $p$ ' as equivalent to 'believing that not- $p$ ', but nothing that I aim to do here hinges on this treatment. The equivalence can be doubted; see Smart (2020) "Disbelief is a Distinct Doxastic Attitude".

3 Among others, see Hájek (1998), Wedgwood (2002), Bergmann (2005) and Friedman (2013b).
} 
i. Cognitive Contact Any account of agnosticism must make sure that a subject cannot be agnostic toward a proposition (or a question) if she is not or never was in cognitive contact with this proposition (or question).

\subsubsection{Proper End}

The obvious solution for non-belief accounts to avoid the problem above would be simply to add Cognitive Contact in the form of a second necessary condition for agnosticism, as Hájek (1998, p. 206), Wedgwood (2002, p. 272) and Bergmann (2005, p. 421) do. However, even with this modification it is still the case that nonbelief is insufficient for agnosticism. Friedman (2013b) has provided several examples in which a subject starts considering the truth of a proposition that she had never thought about before, but, because of various interruptions, never comes to the point where she actually suspends. In such cases, the necessary condition of cognitive contact is satisfied (because the subject entertains $p$ in thought) and $S$ furthermore is in the state of non-belief ( $S$ does not yet believe or disbelieve that $p$ ). But since deliberation may go on for a while before $S$ eventually suspends, it is possible that $S$ is interrupted at a time before she successfully entered the state of agnosticism. In such cases, $S$ opts out "in the midst of fixing one's take on $\Phi$ " (Sturgeon 2010, p. 136) or "mid-wondering" (Friedman 2013b, p. 170) and thus never takes the last step of actually suspending.

This brings us closer to the intuitive view I stated at the beginning: suspension is the relevant act or event by which doxastic deliberation about some matter is put to an end in a certain way such that the subject enters the state of agnosticism. Sean Crawford, who suggests a meta-cognitive analysis of suspension, or reservation of judgment, also subscribes to this idea when he states that "the deliberative process terminates in a reservation of judgment with respect to $p$ " (Crawford 2004, p. 226, my italics). Similarly, Kurt Sylvan points out that "among other things, an agnostic about $p$ would conclude inquiry by being resistant to believing $p$ and being resistant to disbelieving $p$ " (Sylvan 2016, p. 1652, my italics). In her 2013b paper, Friedman explicitly supports the intuitive view that suspension is the relevant act or event that concludes a deliberative process such that the subject enters the state of agnosticism:

Suspending judgment then can be thought of as one way of terminating a deliberative process and (other things equal) moving into a more settled state, viz., a state of suspended judgment or agnosticism. Suspending then is (other things equal) a way of (at least temporarily) terminating a deliberative process that is sufficient for getting into a state of agnosticism. (Friedman 2013b, p. 179, my italics)

Given this intuitive view and its broad acceptance, I suggest that an account of agnosticism must meet the requirement I call Proper End.

ii. Proper End An account of agnosticism should be able to explain the difference between subjects who close deliberation by suspending and those 
who either drop out prematurely or close deliberation in some other way than by suspending.

Friedman's position in her 2013b paper is in tension with the central claim of a later paper (2017), namely, that suspension is the core interrogative attitude and the beginning of all inquiry. ${ }^{4}$ This view has led to a new discussion about different kinds of suspension, some of which are characterized as inquiry-closing, whereas others are characterized as inquiry-opening. Lord (2020) and Sylvan (forthcoming), for example, distinguish kinds of suspension in terms of "interrogative and antiinterrogative attitudes", and Julia Staffel argues that one kind of suspension belongs to the group of "terminal attitudes we reach when we have finished a deliberation"(Staffel 2019, p. 284), whereas another kind belongs to the group of "transitional attitudes" that are formed at the start of or during deliberation. Although I share the view that there are different kinds of doxastic suspension, I think that only the inquiry-closing kind eventually leads to agnosticism. If we agree that agnosticism is a settled state, it is only the inquiry-closing kind of suspension that is of interest to my project here. Proponents of inquiry-opening suspension indirectly support the view that settling is closely connected to closing the question. Staffel, for example, contends that transitional, that is, inquiry-opening attitudes "lack the stability and settledness of terminal attitudes" (p. 286); and Errol Lord states that "anti-interrogative [inquiry-closing] attitudes involve agnostic determination", (Lord 2020, p. 136) whereas interrogative attitudes do not. ${ }^{5}$

As we can see, the requirement Proper End is not in opposition to the view that there is also an inquiry-opening kind of suspension; it only restricts the kind of suspension that leads to the settled state of agnosticism to those acts or events that close inquiry. ${ }^{6}$ The settled state of agnosticism, as I understand it, is only achieved by ending, terminating, or closing inquiry by an act or event we call suspending. This requirement is not a requirement for an account of suspension in general but rather a requirement for an account of agnosticism that has to identify the relevant act or event that brings deliberation to an end and moves the subject into the agnostic state. In order to make sense of the doxastic triad (belief, disbelief, agnosticism) the kind of suspension required for entering the settled agnostic state has to have the same terminal effect on deliberation as the adoption of belief and disbelief has. ${ }^{7}$ Coming back to Friedman's view, this act or event seems best captured by the adoption of an attitude.

\footnotetext{
4 I will not discuss this tension here. See recent discussions of Friedman's new position by Archer (2018; 2019), Atkinson (2021), Masny (2020), McGrath (2021).

5 I have to point out, though, that the concept of a 'settled stance' is used differently by different authors. For example Lord and Sylvan (forthcoming) contend that " $[\mathrm{b}]$ oth sorts of attitudes are forms of settled neutrality" (p. 10).

${ }^{6}$ I want to thank an anonymous reviewer who suggested addressing this point in more detail. I will come back to this when I introduce the requirement Commitment in Sect. 2.2.2.

7 Friedman (2019) argues for (flat-out) belief having exactly this effect on inquiry (in contrast to credences): "Having a belief means having a settled opinion since (normally) a $p$-believer isn't also inquiring into questions that have $p$ as a complete answer" (p. 307). My claim that the kind of suspension relevant to the settled state of agnosticism is required to end inquiry does not deny the existence of
} 
Note that talk of ending a deliberation process properly and (not) ending it prematurely is not meant to indicate a normative requirement for the subject involved. Premature interruption can occur in cases where a subject should have closed the matter long before, but still engages in irrational deliberation, such as when $S$ constantly checks on something where, objectively, no new evidence or insight is to be gained. Additionally, a subject may close deliberation properly by suspending even if, from a rational point of view, there might still be lots of evidence to be reviewed and deliberated about. A descriptive account has to allow for irrational suspension and agnosticism. ${ }^{8}$

\subsubsection{Lost Reasons}

In another move against non-attitude accounts of agnosticism, Friedman argues that these accounts provide bad results for cases in which subjects lose the reasons for which they originally suspended but nonetheless remain agnostic.

According to Friedman, we want to allow for subjects to remain in the agnostic state after having lost their original reasons because "reasons look separable from the state" (Friedman, 2013b, p. 176). Let us agree with Friedman that an account of agnosticism needs to make sure that the agnostic state can be upheld independently of whether the reasons for which one originally entered that state are at some later time defeated or not. Further, we want an account of agnosticism to allow that subjects forget the reasons for which they suspended without thereby leaving the agnostic state. All of these cases speak for the Lost Reasons requirement:

iii. Lost Reasons An account of agnosticism must allow that $S$ continues to be agnostic despite having lost the reasons for which $S$ originally entered that state.

Note that Lost reasons is no rationality requirement either. It is one question whether subjects should keep track of the relations between their mental states and their reasons for being in these states and another question whether they actually do. No matter how the normative question will be answered, findings in cognitive psychology suggest that we often do stick to our beliefs even if the relevant reasons have been defeated. ${ }^{9}$ There is no good argument why this should be any different with agnosticism. If we think that subjects typically enter the state of agnosticism

Footnote 7 continued

inquiry-opening suspension. The only thing I do deny is that inquiry-opening suspension leads to a settled state of agnosticism. I don't mean this to be a disagreement about words, but the traditional use of the 'agnostic' is someone who does not know and is content with this being so. The traditional mind-set of the agnostic does not contain an intrinsic motivation to find the answer one lacks by actively inquiring further. This does not mean, of course, that agnosticism cannot be temporary. It only means that for the time the subject is agnostic, she does not inquire into the matter she is agnostic about.

8 In Wagner (forthcoming), I argued that suspension is indeed a way to avoid epistemic conflict. In cases in which a subject's conflict stems from a genuine epistemic dilemma, it is clearly irrational to suspend though it is the best a subject can do in this situation to settle her conflicted state of mind (despite remaining in the dilemmic situation).

9 See Anderson (1995), Anglin (2019) and Nestler (2010). 
for a reason, then a descriptive account of agnosticism needs to provide the means to cover phenomena where subjects lose their reasons for agnosticism but nonetheless remain in the agnostic state.

\subsubsection{Summary}

The overall lesson from Friedman (2013b) is that accounts involving an attitude fare best at accommodating the view that a subject enters the state of agnosticism by an act or event that closes doxastic deliberation in the right way. In light of the three discussed requirements, it is fair to say that (i) the presence of an attitude toward a proposition or question guarantees cognitive contact of the relevant sort, (ii) the proper way of bringing deliberation to an end can best be captured by the formation of an inquiry-closing attitude, and (iii) an attitude and the reasons for which the attitude has been formed are separable from each other.

However, at this point, nothing has been said about the kind of attitude that is suitable for bringing the subject into the state of agnosticism. In the next section, I will introduce further requirements that concern the nature of the sought-after attitude, its object, and the resulting structure of the (potentially complex) state of agnosticism. I will discuss whether and how competing attitude accounts of agnosticism meet these requirements and point out some problems. In particular, I will focus on Friedman's non-reductive account of a sui generis attitude and on different meta-cognitive accounts that reduce agnosticism to a complex state that has as its core element a certain belief about one's own deficient epistemic situation.

\subsection{Indecision and agnosticism}

In this section, I will mainly discuss the distinction of the mental states of indecision and agnosticism, as well as the transition from one to the other. In Sect. 2.2.2, I will explore the relevant additional component that accompanies agnosticism but is absent in merely undecided subjects. I will argue in accordance with most contributors that unlike the merely undecided subject, the agnostic subject is committed to indecision for a reason and that this commitment is best captured by means of an attitude. My interpretation of what it is to commit to indecision will be very different from other accounts, though.

In Sect. 2.2.3, I will ask what a subject is doing when she revises her agnostic stance in a situation in which her initial reasons for agnosticism have been rebutted or undercut. An adequate theory of agnosticism, so I argue, has to be able to account for the difference of undercutting and rebutting defeaters for agnosticism, and I will show that this is done best by paying attention to the internal structure of the complex mental state of agnosticism. However, before I turn to the requirements Commitment and Revision, I need to elaborate further on the mental state of indecision or doxastic neutrality that is crucial for agnosticism. 


\subsubsection{Doxastic neutrality}

In Sect. 2.1, we saw on the basis of Friedman's counterexamples that non-belief accounts fail to establish a subject's agnosticism and that an attitude needs to be involved to make sure that the subject enters the state of agnosticism in the proper way and for a reason. But what is it that makes the mental state of agnosticism a doxastic stance? Plausibly, the relevant feature that makes agnosticism with respect to $p$ a doxastic stance is the fact that an agnostic subject is undecided or neutral regarding $p$ 's truth. In contrast to mere non-belief, doxastic indecision or neutrality has to have some (at least minimal) bearing on the evidence the subject has (or the fact that there is none). Arguably, a subject who neither believes nor disbelieves that $p$ is true can be described as doxastically neutral (or 'merely' undecided) regarding $p$ 's truth only if she meets the requirement Cognitive Contact.

Friedman, however, promotes a sui generis attitude of 'being agnostic' that is in itself indecision-representing and concludes from this perspective that "non-belief is not required (except rationally, perhaps)" (Friedman, 2013b, p. 169) for an account of agnosticism after all. By contending that " $\mathrm{t}]$ he indecision of the agnostic is not the indecision of mere non-belief" (p. 177), Friedman seems to assume that there are two kinds of indecision that differ with respect to their nature and can be found in subjects independently of each other. ${ }^{10}$ It is, however, only because of a peculiarity of the promoted sui generis attitude that the indecision of mere nonbelief seems not to be required for describing the subject's agnosticism, or so I will argue.

Let me illustrate this with the help of the meta-cognitive account that Friedman explicitly mentions as a possible candidate for an attitude account of agnosticism: "One plausible option that has emerged is that the attitude one has when one suspends about $p$ is just a belief: in particular a belief about one's (somehow deficient) first-order epistemic or doxastic standing with respect to $p$ " (p. 180). Friedman contends that "thoughts about one's own epistemic perspective on whether or not $p$ are plausibly indecision-representing attitudes (with respect to $p$ )" (p. 175). However, it is important to understand that a sui generis attitude of being agnostic represents indecision in a very different way than the meta-cognitive belief regarding one's epistemic stance does. Whereas the assumed attitude of 'being agnostic' is supposed to represent or express the subject's indecision toward the respective proposition or question that is its object, the attitude of believing obviously does not. To the contrary, if $S$ believes that $p$ is true, then $S$ is not undecided or neutral with respect to $p$ 's truth.

Rather, $S$ 's meta-cognitive belief represents (according to the view of the metacognitivist at least) $S$ 's indecision toward a proposition $p$ because of the content of her belief, that is, her deficient epistemic perspective regarding $p$. The content of the meta-belief is not the proposition $p$ which $S$ is supposed to be undecided about but

\footnotetext{
${ }^{10}$ In her 2017 paper, this view is even clearer: "In taking the attitudinal approach to suspension for granted I take it that $S$ 's not believing that Rover broke the vase and not believing that he didn't break the vase is not sufficient for $S$ 's suspending judgment about whether Rover broke the vase. In fact, I don't think that $S$ 's lacking those beliefs is necessary either" (Friedman, 2017, p. 305).
} 
another proposition that represents $S$ 's epistemic situation with respect to $p$. Therefore, it is not in virtue of the attitude of believing that the subject counts as undecided, but in virtue of the content that she believes: for example, that she is in an epistemically problematic situation with respect to the truth of $p$, that she ought not to adopt a belief regarding $p$ given her evidence, or that it cannot be determined whether $p$ is true or not. ${ }^{11}$

All of these contents have one thing in common: they represent or express the subject's doxastic neutrality regarding the truth of $p$ by means of non-belief with respect to $p .{ }^{12}$ Thus, for meta-cognitive accounts, it is not the case that, as Friedman thinks, "the indecision of mere non-belief is not required". This may also be true for other reductive attitude-accounts of agnosticism that are not indecision representing in the particular way of the sui generis attitude of being agnostic. Hence, the question of whether the indecision of non-belief is (or is not) necessary for describing agnosticism depends on the question of whether a subject's indecision can or cannot be properly captured by the respective account in some other way. To keep open the different ways of modelling the state of agnosticism (at this point of the paper at least), I suggest the following modest requirement:

iv. Doxastic Neutrality An attitude account of agnosticism has to explain according to which feature an agnostic subject is genuinely undecided or neutral regarding the truth of the matter in question.

As we have seen, Friedman's sui generis attitude of being agnostic is defined such that it expresses or represents the subject's indecision regarding a proposition or question by itself. Additionally, her notion of agnostic indecision is psychologically independent from the indecision that comes with non-belief. The ontological commitment to two different kinds of indecision is not particularly parsimonious and it seems difficult to explain why the agnostic is undecided about the truth of a proposition in a genuinely different way than the merely undecided subject. I will further elaborate on this in the next section.

\subsubsection{Committing to indecision}

As we saw in the last section, mere indecision in the form of non-belief does not qualify for agnosticism. On this point, there is no disagreement between the

\footnotetext{
11 Different meta-cognitivist accounts suggest different contents for the relevant meta-belief. Crawford (2004), for example, contends that, as an agnostic, one has "thoughts about one's own epistemic perspective on whether or not $p$, namely, that one's epistemic perspective falls short of establishing whether $p$ " (p. 226). Rosenkranz (2007) takes "the assertion that we are neither in a position to know $p$ nor in a position to know " $\neg p$ ", as required for his notion of "True Agnosticism" (p. 461). Raleigh (2021) introduces the "belief or opinion that one cannot yet tell whether or not $p$ " to be based on one's evidence (p. 2455).

12 In fact, most meta-cognitivists take non-belief to be necessary for agnosticism. Crawford: "since to suspend judgement with respect to something is (at least) neither to believe nor disbelieve that thing" (Crawford, 2004, p. 224); Raleigh: "Suspending whether $p$ also requires that the subject is in a neutral doxastic state with respect to $p$-i.e. she neither believes that $p$ nor disbelieves that $p$ " (Raleigh, 2021, p. 2457).
} 
proponents of a sui generis attitude account and a meta-cognitive account of agnosticism. So what exactly is it that a merely undecided subject lacks but the agnostic subject exhibits? It is often said that the agnostic state of mind brings with it a certain commitment to indecision that is absent from the mental state of the merely undecided. ${ }^{13}$ Meta-cognitivists and proponents of the sui generis approach further agree that an attitude account seems best suited to deliver the relevant commitment to indecision, because the formation of an attitude typically comes with a certain commitment. Different attitudes, however, come with different commitments, and details are needed about what kind of commitment is required for agnosticism.

Generally, there are two ways of understanding a subject's commitment to indecision: (A1) The commitment to indecision can be understood as the subject's aim to not yet decide with respect to the truth of some matter and as such can be regarded as bringing about or maintaining the mental state of indecision. This is plausible when we think of a subject who aims to make up her mind about some question in an impartial or neutral way, or simply to find out the truth about some matter. (A2) Alternatively, a commitment to indecision can be understood as a qualification or an assessment of one's de facto indecision, that is, the state of indecision in which the subject finds herself regarding the truth of some matter. By committing to her own indecision in this way, the subject does not have the aim of being in a state of indecision but rather assesses the fact that she is in that state.

We can address this difference between the two ways of being committed to indecision from the perspective of inquiry: in the former description of a commitment to indecision as in A1, a subject temporarily commits herself to neither believing nor disbelieving $p$ for the purpose of reviewing or gathering relevant evidence. This commitment has the subject bound to holding back any potentially premature judgment with respect to $p$ for the sake of an impartial and critical assessment of the evidence. This fits well with the description of suspension involving an "interrogative attitude", as has been proposed by Friedman (2017), Lord and Sylvan (2020; forthcoming) and also Staffel (2019). The attitudes they suggest come with a commitment to becoming or remaining (at least temporarily) undecided to support and guide a subject's inquiry into some matter.

The alternative description of a commitment to indecision relates to inquiry in the opposite way. A subject who commits to indecision per A2 is already undecided with respect to the matter in question, typically because of her deficient evidential situation. The subject's commitment here is a commitment to her de facto state of indecision (with regard to $p$ ) and results in stopping further inquiry (into $p$ ). The subject's formation of the attitude in question is some sort of assessment or

\footnotetext{
13 See, for example, Rosenkranz (2007): "True Agnosticism [...] is stable enough to generate commitments with respect to the debate's future course, and thus is more than a mere refusal to adopt any stance at all” (p. 101); Sturgeon (2010): “[S]uspended judgment is a non-trivial kind of judgement, a nontrivial kind of committed neutrality. The joint absence of belief and disbelief is no kind of judgement at all, no kind of commitment" (p. 136); Friedman (2013b): "Non-belief cannot be the agnostic's only sort of indecision. But how else can we capture $S$ 's indecision now except by way of an attitudinal commitment to indecision?" (178); Sylvan (2016): "Agnosticism consists in settled resistance to belief on the evidence—a committed neutrality relative to one's evidence" (p. 1653).
} 
evaluation of her own doxastic state of indecision: in the context of her evidential situation, $S$ may assess her indecision to be appropriate, permissible, or even obligatory, take her evidence to be inadequate to decide the issue at the moment and may even judge the question at hand to be undecidable. In such cases, $S$ 's indecision is the object of her commitment, not its aim. By taking a stance toward her own doxastic state regarding $p, S$ (at least temporarily) terminates or suspends further inquiry into the question whether $p$. It is fair to say that suspension in the form of an "anti-interrogative attitude" (Lord, 2020) or a "terminal attitude" (Staffel, 2019) is perfectly compatible with my proposed commitment to indecision as in A2 (even though the quoted authors follow a different agenda than is suggested here).

I want to argue that the second way of understanding a subject's commitment to indecision (A2) is suited to distinguishing the merely undecided subject from the agnostic subject. The termination of inquiry by a subject's commitment to her own mental state of indecision provides the required stability or settledness of agnosticism that the merely undecided subject lacks. By assessing her own doxastic state of indecision regarding $p, S$ gains a settled perspective with respect to the truth of $p$ without having established whether $p$ is true or not. $S$ enters the state of agnosticism via forming an attitude by which she commits herself to her own de facto indecision and terminates inquiry. A subject who commits to this fact identifies with her own indecision and adopts her indecision as her own. Committing to indecision in this way is the relevant step toward agnosticism that the merely undecided subject lacks. The theistic agnostic, for example, settled on a neutral opinion with respect to the existence of a god and does not inquire the issue any further. Sure, there may be circumstances that, if the agnostic were to face them, would even lead her to change her view, but this is no different with any other settled opinion like that of belief or disbelief. ${ }^{14}$

The commitment to being undecided per A1, however, cannot be the kind of commitment needed for agnosticism. If a subject is committed to refrain from adopting any doxastic stance for the sake of inquiring further into the matter, then the agnostic stance is among those things that $S$ aims to avoid. Simply put, the point of committing to indecision in terms of A1 is not to settle the issue in question at this point. $^{15}$

Thus, the fifth requirement for an account of agnosticism is to explain the nature of the commitment to indecision that distinguishes the agnostic's mindset from that of the merely undecided subject in the following way:

\footnotetext{
14 Similar points have been made by Friedman (2013b, p. 173) and Raleigh (2021, p. 2468).

15 It may seem inappropriate, though, to refer to a subject who aims at keeping an open mind for the sake of inquiry as "merely" undecided. Adopting and maintaining this state of mind clearly requires a more sophisticated mental setting than the mere absence of belief and disbelief with respect to some proposition one entertains in thought. In some cases, substantive mental effort will be required for not jumping to conclusions and remaining undecided despite there being all kinds of temptations to make an early call. Nevertheless, a subject who fights off these temptations to believe or disbelieve $p$ in the process of a thorough deliberation with the aim of finding out the truth is not agnostic with respect to $p$ because she treats the question of whether $p$ as open and has not yet settled on a position regarding that matter.
} 
v. Commitment An attitude account of agnosticism has to capture the subject's commitment to indecision by means of an attitude such that the subject settles her de facto indecision regarding a proposition or question and stops further inquiry.

Let us consider the two popular attitude accounts and the attitudes they suggest for capturing the agnostic's commitment to indecision. Do these attitudes meet requirement $v$ ? One might think that a sui generis attitude of 'being agnostic' can simply be defined to bring about the right kind of commitment for agnosticism. It is problematic, however, that the primitive state of agnosticism does not have any internal structure that could explain the subject's commitment to her de facto indecision as an act of assessing her own doxastic state. Hence, we can only stipulate that being in this state not only expresses the subject's doxastic indecision regarding the truth of $p$ but also brings with it the relevant commitment to this indecision regarding $p$. Because the indecision and the commitment to this indecision are not separable, the sui generis account has less explanatory force, so I argue. In the next section, I will explain why this lack of structure within the primitive state of agnosticism creates an additional problem in the context of revising one's agnostic state in the face of undercutting defeaters.

Meta-cognitive accounts, it would appear, are in a better position here because, in principle, they have the required structure to meet Commitment and thereby explain the subject's assessment of her own indecision. Not all meta-cognitive accounts, however, use this structure in the way Commitment describes. I will briefly discuss two different meta-cognitive approaches, one that Sean Crawford suggested and the other that Thomas Raleigh suggested, and explain why I think that they both ultimately fail or are at least insufficient for agnosticism.

Crawford (2004) suggests that "[s]uspension of judgement necessarily involves thoughts about one's own epistemic perspective on whether or not $p$, namely, that one's epistemic perspective falls short of establishing whether $p$ and thus that one does not know whether $p$ " (p. 226). Clearly, by forming a belief regarding one's deficient epistemic situation, the subject takes a stance toward her own indecision. But can the attitude of believing deliver the right kind of commitment that puts an end to inquiry and settle the question whether $p$ ? I don't think so. Why would believing that I am undecided due to insufficient evidence keep me from further inquiring into the matter of $p$ ? $S$ may come to believe that she is undecided about the truth of $p$ and that she is undecided due to her lack of evidence. Nevertheless, she may be motivated to change this fact about her doxastic state regarding $p$ and start a thorough investigation into the matter with the aim of finding out whether or not $p$. This is not what the agnostic does. I agree that any assessment of one's own indecision requires that one be aware of one's own indecision - and in this respect, my account will be very close to the meta-cognitive view. Ultimately, though, I do not think that the awareness of one's doxastic state alone can be sufficient for establishing the transition from being merely undecided to being agnostic. ${ }^{16}$

\footnotetext{
16 To be fair, Crawford does not claim that forming the relevant meta-belief suffices for agnosticism; he only takes it to be necessary for suspension.
} 
Raleigh (2021) takes another approach to meta-cognitivism. Similarly to Crawford, he argues that "[s]uspending whether $p$ constitutively requires having a belief or opinion that one cannot yet tell whether or not $p$, based on one's evidence" (p. 2455). This meta-belief, according to Raleigh, provides the relevant commitment to indecision only if the meta-belief serves as an explanatory and a motivating reason for the subject to neither believe nor disbelieve the proposition in question: "we want the meta-cognitive belief to be the subject's motivating reason for the doxastic neutrality and not just a merely causal-explanatory reason" ( $p$. 2457). In this setting, the answer to the question of how to distinguish the merely undecided subject from the agnostic can thus be spelt out in two ways: Either the merely undecided subject's indecision is pictured as an uninformed state that is not related to her epistemic situation because she, in contrast to the agnostic, simply lacks the essential meta-belief and does not reflect on her epistemic situation at all; alternatively, the merely undecided subject can be described as an irrational subject who, while having formed the relevant meta-belief, is not motivated by it. In the latter case, the difference between the merely undecided and the agnostic would be a matter of rationality.

Let us consider the commitment to indecision that Raleigh proposed. As it stands, the commitment that comes with the attitude of belief cannot be the commitment that is characteristic of agnosticism, because, as Raleigh emphasises, merely having the required meta-belief does not yet guarantee that the subject actually takes it as a reason for her indecision. Therefore, there seems to be an additional commitment to act on one's meta-belief and take it as a reason for one's doxastic neutrality. So what exactly what does it mean to take one's meta-belief as a reason for one's neutrality? What kind of act or event is this supposed to be?

Here is a plausible scenario: $S$, let us assume, starts out believing that $p$ but then reconsiders her evidence and forms the meta-belief that she actually cannot yet tell whether or not $p$ is true. In this situation, $S$ will, if rational, take the newly acquired meta-belief as a reason for giving up her initial belief that $p$. After having dropped the initial belief that $p, S$ ends up in the state of non-belief with regard to $p$ and, thus, is neutral or undecided about $p$ 's truth. Here, it is indeed true that $S$ 's newly acquired indecision regarding $p$ is causally explainable and motivated by her metabelief, which $S$ took as a reason for giving up her former belief that $p$. Indeed, in this case $S$ commits to indecision by taking her meta-belief (that her epistemic position with respect to $p$ 's truth is deficient) to be a reason for dropping her belief that $p$. However, by doing so $S$ does not settle her indecision in the sense of A2, as is required for agnosticism, but rather in the sense of A1. The resulting state here is not a qualification of one's indecision but only indecision simpliciter. $S$ takes the metabelief to be a reason to become undecided by dropping the belief that $p$.

Not every mental process that leads to indecision is achieved by dropping an initial belief in the way described above. It is also natural that a subject starts deliberating into $p$ 's truth while she is already undecided (in the sense of $p$-nonbelief) and then, after having reviewed the evidence, forms the meta-belief that she cannot yet tell whether or not $p$ is true. It is a natural process to start deliberating into something one does not know and then realize that the evidence is insufficient to decide the issue after all. According to Raleigh's view, the subject I described 
counts as agnostic only if her indecision is motivated and explained by the metabelief that she acquired during deliberation. Since this subject is undecided regarding $p$ at all stages of her deliberation, it is difficult to identify the act for which the meta-belief is taken to be the motivating reason. Thus, the question arises what there is left to do for the prospective agnostic subject such that she can be properly described as being motivated by her meta-belief. What mental act is the meta-belief a reason for? It is unclear how to describe the natural transition from mere indecision to agnosticism that is motivated and explained by the meta-belief if the required connection between the subject's meta-belief and her resulting indecision is not brought about by an additional mental act or event that is different from the formation of meta-belief itself.

As an anonymous reviewer suggested, the relevant decision that distinguishes the merely undecided and the agnostic subject could be the decision to remain undecided: whereas the agnostic subject thinks or is disposed to think "Given my evidence, I cannot tell whether $p$ or not- $p$, and on this basis, I should not believe either $p$ or not- $p$ ", the merely undecided subject does not think or is not disposed to think this thought. I agree that this distinction helps to distinguish (rational) subjects who respond to their meta-belief and (irrational) subjects who do not. But I do not think that this is a distinction between those who are merely undecided and those who actually entered the state of agnosticism. I want to respond to this suggestion by arguing that being disposed or even motivated to think a normative thought does not suffice for the subject to act on its content.

Suppose I subscribed to Skepticism because I thought that, given the evidence, I should not believe that there is an outside world and I also should not believe that there is no outside world. Ultimately, however, I fail and just do believe that there is an outside world. This is perfectly compatible with still upholding the meta-belief that I really should not believe or disbelieve that there is an outside world given the evidence. Even though my meta-belief makes me have these thoughts about how I should behave doxastically, I just fail in doing so. This may be irrational, but it is not impossible and I think it happens a lot that we have beliefs that we think we ought not to have given the evidence. ${ }^{17}$ The conclusion I draw from this is that merely thinking a thought with a normative content is insufficient for actually doing what is rationally demanded given that I believe the content. Hence, I think that the basic meta-cognitive view needs an additional act (for which the meta-belief can serve as a motivating reason) that is not itself a belief or a disposition to think certain thoughts. In the second part of the paper, I will explain in more detail what kind of act $\mathrm{I}$ have in mind. ${ }^{18}$

\footnotetext{
17 We know that racist and sexist thoughts or stereotypes of any kind can occur in a similar setting where people realize that they actually have beliefs they think they should not have. It is not always easy to drop them even if having the right kind of dispositions to think what is to believe or not to believe.

18 I want to thank an anonymous reviewer for pressing me on this point.
} 


\subsubsection{Revising agnosticism}

The different attitude accounts of agnosticism agree that the agnostic state is motivated by a reason and can be rendered more or less justified in light of the respective motivating reasons. Reasons can be defeated, though, as we have seen in the discussion of the requirement Lost Reasons in Sect. 2.1.3. Friedman uses an intriguing example to show that losing one's reasons for agnosticism does not automatically lead to a change of mind. People may stick to their agnostic mindset even if the reasons for which they originally entered that state have been defeated. In this section, I want to argue that even if it is correct that losing one's reason does not guarantee a change of mind, it can lead to that result, and it is plausible that, in some cases, it actually does. An account of agnosticism needs to be able to explain both of these outcomes if the relevant reason for having entered the agnostic state has been defeated: (a) the subject does not change her mind and remains agnostic, and (b) the subject does change her mind about the issue in question and gives up her agnosticism. Whereas the Lost Reasons requirement deals with outcome (a), I want to attribute the requirement Revision to outcome (b).

We established in the last section that subjects enter the agnostic state by committing to their de facto indecision. If $S$ commits to her indecision for a reason, $S$ may give up her commitment once her reason is defeated (and she is aware that this is so). There are two points worth discussing: first, reasons can be defeated in different ways which have to be taken into account; and second, because the structure of agnosticism in terms of committing to one's indecision is more complex than first-order doxastic states like belief or disbelief, this will have consequences for the question of how to revise one's agnosticism.

Consider the case of a subject who is agnostic with regard to a proposition $p$ and then comes across new evidence containing a prima facie reason for believing (or disbelieving) $p$. A prima facie reason like this may also be called a rebutting defeater. Clearly, if $S$ is rational and encounters evidence that speaks for the truth of $p$, then $S$ will start believing that $p$ is true and thus will stop being undecided about $p$ 's truth. If agnosticism is a commitment to one's de facto indecision, a rational subject has to retract this commitment: by believing $p$ to be true, she is not undecided regarding $p$ 's truth anymore. Although it is conceptually impossible that $S$ is undecided and decided with regard to $p$ 's truth at the same time, we could think of an irrational subject sticking with her past commitment to her former indecision even though she is not undecided anymore. A structure that separates one's indecision and the commitment to one's indecision is able to explain what is going on in these cases.

For example, we could think of a subject who has been agnostic about $p$ for most of her life and then (maybe against her practical interests or dogmatic belief system) comes to believe that $p$ on the basis of new evidence that she cannot ignore. Despite forming the belief that $p$, she may encounter psychological difficulties with regard to disowning her long-kept commitment to indecision regarding $p$, and her cognitive adaptation to the new reality may take a while. It seems plausible to say that she believes that $p$ and is thus not undecided with respect to $p$ 's truth, but still is committed to her former indecision. This is clearly irrational, and the normative 
profile of agnosticism cannot allow for this mindset. Therefore, the structure of the agnostic state makes it necessary to check for the rationality of indecision and that of the commitment to indecision separately. ${ }^{19}$

Consider another case of a subject $S$ who is agnostic with regard to a proposition $p$ and then comes across new evidence that undermines her original reason for agnosticism but which, at the same time, does not constitute a reason against $S$ 's indecision with respect to $p$. We may call a reason like this an undercutting defeater. ${ }^{20}$ In a situation like this, it is rational for the subject to remain undecided because she has no reason for believing or disbelieving that $p$ is true. However, she is required to give up her commitment to her indecision. I will argue with the help of an example that this situation can only be captured by an account of agnosticism that separates a subject's indecision and her commitment to that indecision. Before doing so, let me first propose the last requirement for an account of agnosticism.

vi. Revision An account of agnosticism has to be able to explain the transition from agnosticism to other doxastic states (including non-agnostic indecision) due to different kinds of defeaters.

Let's see how such a change of mind can be described for a situation similar to Friedman's NASA example, where the reason for one's agnostic state has been undercut but no prima facie reason for believing or disbelieving has been provided in its place. I want to argue that the transition from agnosticism to mere indecision is a substantial change of mind, even if this transition does not change the fact that the subject is "still very much in the dark" (Friedman 2013a: 176) about the truth of the proposition in question. How can attitude accounts of agnosticism explain this change of mind?

To discuss the transition from agnosticism to mere indecision, let me introduce Marta: Marta entered the agnostic state with regard to Martian life at time $t_{1}$ for the prima facie reason that technical limitations make it impossible to determine whether or not there is life on Mars. At some later time, $t_{2}$, she learns about NASA's new method, which can clearly determine whether or not there is life on Mars. Let us assume that NASA will host a press conference later that day where the results will be released, but they are kept secret until then. Sure, Marta could just remain agnostic, but it is also plausible that Marta gives up her agnosticism in this situation and starts deliberating anew whether Martians exist while desperately waiting for the results to be released. How can Marta's change of mind be explained by the two

\footnotetext{
${ }^{19}$ Friedman (2017) argued that a doxastic conflict between believing and suspending should be possible: "But once we admit that doxastic conflict is possible, why shouldn't we admit that possibility in full generality? Just as a subject can be conflicted with respect to her beliefs on some matter, she should be able to be conflicted with respect to her beliefs and suspendings on some matter" (p. 305). Given that one wants to allow for a conflict between one's commitments that come with agnosticism and those that come with belief, then the situation of the long-term agnostic who adopted a belief I spelt out above seems to be a plausible case. Having said this, I am reluctant to call this a proper conflict between belief and agnosticism.

20 The distinction between undercutting and rebutting defeaters goes back to John Pollock's theory of defeasible inference (Pollock, 1987).
} 
accounts I discussed before? In virtue of what is Marta withdrawing her commitment to indecision while remaining undecided?

According to the sui generis approach, Marta entered the state of agnosticism by adopting the attitude of 'being agnostic' for the reason that technical limitations prevent any insight with respect to life on Mars. When this reason was undercut by NASA's announcement of its new technique, Marta (being rational) revised her doxastic stance by giving up her attitude of 'being agnostic'. Because the sui generis approach considers agnosticism to be a primitive state that has no further structure, Marta cannot just revise her commitment to indecision but keep the doxastic neutrality she originally exhibited before committing to it. For the sui generis approach, giving up her commitment comes with giving up her (agnostic) indecision toward life on Mars. This does not seem problematic if Marta is still undecided in the non-agnostic way that Friedman calls "the indecision of mere non-belief". However, because these two kinds of indecision are independent from each other, there is no guarantee that Marta actually is undecided in this way. And if she does turn out to be undecided in this non-agnostic way, this is not necessarily the result of her giving up her commitment to indecision because of an undercutting defeater. Again, the lack of structure of the primitive state of being agnostic lacks explanatory force.

Marta's case is more complicated when we apply it to the meta-cognitive accounts I discussed in the previous section. Because Raleigh's account provides more details regarding the reasons involved, I will concentrate on his account in this section. According to Raleigh, the meta-belief that one cannot yet tell whether there is life on Mars given the evidence is the relevant reason that motivates and explains Marta's commitment to indecision. Hence, if this reason is lost and the subject is rational, she will give up this commitment and leave the agnostic state.

Let us assume that Marta formed the meta-cognitive belief (that she cannot tell whether there is life on Mars given her evidence) solely for the reason that technical limitations make it impossible to determine whether or not there is life on Mars. It is this latter reason that motivates and explains Marta's meta-cognitive belief. When she finds out that NASA has developed a new technique that can resolve the issue, Marta's reason for her meta-cognitive belief is defeated (or more precisely: undercut). What does Marta have to do from a rational point of view? Since she lost her sole reason for her meta-cognitive belief, Marta is rationally required to drop it. Consequently, by dropping the meta-belief, Marta loses the sole reason that motivated and explained her doxastic neutrality: "within the complex state of suspending judgement, one constituent — the meta-cognitive belief — is the subject's reason for the other constituent-the doxastic neutrality" (Raleigh, 2021, p. 2457). In the end, it seems, that, according to this view, Marta has to give up not only her commitment to doxastic neutrality but also her doxastic neutrality altogether. This is a strange result because Marta still lacks any prima facie reason to believe or disbelieve that there is life on Mars.

Maybe one could avoid this problem by saying that Marta does not have to give up her meta-belief because even after NASA's announcement it is still true that Marta cannot tell whether there is life on Mars. This reply, however, would commit the meta-cognitivist to the view that there are no undercutting defeaters for agnosticism 
in general. This would mean that the meta-belief that one's evidence regarding $p$ 's truth is deficient can, by definition, only be defeated by a prima facie reason that speaks for believing or disbelieving that $p$ is true. According to this view, it would not be possible for a subject to revise her agnosticism regarding $p$ without adopting a belief or a disbelief that $p$ is true. I do not think that this is an appropriate description of what is going on in Marta's case. An account of agnosticism has to provide for the possibility that subjects retract their former commitment but nonetheless retain the doxastic neutrality they started with before having committed to it. ${ }^{21}$

\subsubsection{Summing up}

In the first part of the paper, I introduced six requirements for the intuitive view that suspension is the relevant act or event that commits the subject to indecision and terminates inquiry such that the subject enters the settled state of agnosticism. Although the first three requirements, which I dedicated to Jane Friedman (Cognitive Contact, Proper End and Lost Reasons), do not pose a problem for attitude accounts like the sui generis account or meta-cognitive accounts, the requirements of Commitment and Revision, which concern the transition between mere indecision and agnosticism, create problems for both accounts.

The main problem with a sui generis account is that a primitive state of agnosticism lacks any kind of internal structure that could account for a subject's indecision and her commitment to that indecision as separate. I have argued that the sui generis approach lacks explanatory power with regard to what a subject does when she commits to indecision for a reason given that committing to indecision is understood as a commitment to the neutral doxastic state the subject is already in (I referred to this as "de facto indecision"). Similarly, a sui generis approach cannot explain the transition from agnosticism to mere indecision as a form of retracting the former commitment to one's indecision such that, by default, the subject ends up being merely undecided again. This retraction of one's former commitment (e.g. in the face of undercutting defeaters) is only explainable if the indecision and the commitment to it can be told apart. Further, Friedman's sui generis account assumes two different kinds of doxastic indecision that are supposed to be psychologically independent from each other. It is not intuitive, I think, that the merely undecided and the agnostic subject are undecided about the truth of some matter in fundamentally different ways. Rather, I take it, agnostic indecision is a qualified or settled form of indecision.

In general, meta-cognitive accounts are able to provide the required internal structure to distinguish the subject's indecision (the joint absence of belief and disbelief) and her commitment to that indecision (the meta-belief about her deficient evidential situation). The main worry I have about meta-cognitivist accounts is that believing (that one is in an epistemically deficient situation) is not the right kind of attitude that settles the subject's indecision and brings inquiry to an end. Having

$\overline{21}$ Thanks to an anonymous reviewer for having me clarify this point. 
beliefs about one's doxastic state and one's deficient evidential situation is compatible with ending inquiry, but it is also compatible with starting inquiry or inquiring further. Something else needs to be added to the meta-cognitive view that provides this extra step toward agnosticism.

It is possible that the concerns I raised with respect to both attitude accounts can be explained away by suggesting that there are different kinds of suspension, some of which are inquiry-opening and others that are inquiry-closing. Indeed, I think that there are different kinds of suspension and that they allow for different interpretations of what it is to commit to indecision for a reason, as I discussed in Sect. 2.2.2. Possibly, the neutrality Raleigh and Friedman are after is restricted to inquiry-opening or inquiry-guiding attitudes only, and there is nothing wrong with that. When it comes to agnosticism as a settled state, however, I argued that only inquiry-ending suspension can provide the relevant step to agnosticism.

Friedman addresses the "feeling that suspension of judgment is something that comes at the end of inquiry: after a struggle to answer some question one finally gives up and suspends". She rejects this view partly because it would then be "impossible to inquire into $Q$ while being suspended about $Q$ " (p. 313). I welcome the result that the kind of suspension that leads to the settled state of agnosticism is incompatible with inquiry. By reopening a question, one's doxastic state of agnosticism is unsettled. This is what happens when Marta (see Sect. 2.2.3) revises her agnosticism by retracting her commitment to indecision because the reason for which she suspended originally has been undercut. However, I agree with Friedman that it seems to be wrong to say that no kind of suspension is compatible with inquiry. Surely, it is wise to suspend while inquiring in the sense of staying clear of premature conclusions against one's inclinations to make an early call. But this state is not the state of the agnostic subject that settled on a neutral opinion.

For my own account of agnosticism, I will suggest in the next section that the agnostic committed to her de facto indecision by forming an evaluative attitude that has her own indecision as its object. This endorsing attitude neither brings the subject's indecision causally about nor does it explain the indecision. Thus, the subject can take back the commitment to indecision and start inquiring again without giving up her indecision altogether. I will elaborate on this in the next section.

\section{A two-component analysis of agnosticism}

The mental state of agnosticism, I want to suggest, has to be analysed as a complex state that consists of a structural relation between two components: one component is the subject's doxastic indecision and the other component is the commitment that is directed at her own indecision. The indecision is not explained or motivated by the commitment but evaluated by it. Indecision, I think, is best captured conservatively by the doxastic state of non-belief with regard to a proposition with which one has, or has had, cognitive contact. The commitment to indecision, so I will argue, is provided by the formation of the inquiry-closing attitude of endorsement. These two components stand in the following relation to each other: 
2-C analysis A subject $S$ is agnostic with regard to the truth of a proposition $p$ if and only if $S$ is in the doxastic state of indecision regarding $p$ and endorses the fact that she is in that state.

I will first explain the doxastic state of indecision and then the evaluative attitude of endorsement. After that, I will explain how this account meets all six requirements I have spelt out in the first part and how it avoids the problems I raised for metacognitive and sui generis accounts of agnosticism.

\subsection{Indecision and non-belief}

I will start with my definition of indecision:

Indecision A subject $S$ is undecided with regard to the truth of a proposition $p$ if and only if (1) $S$ neither believes nor disbelieves that $p$ and (2) $S$ is or was in cognitive contact with $p$.

Note that my definition of indecision has the same necessary and jointly sufficient conditions that Hájek and Wedgwood suggested for agnosticism. Mere non-belief, I take it, is not only insufficient for agnosticism, but also insufficient for indecision. It is correct that cavemen are in the state of non-belief with regard to the proposition that quarks exist because they neither believe nor disbelieve that quarks exist; the absence of both a believing and a disbelieving attitude alone may suffice for them being deeply ignorant, but it does not make them undecided with respect to the truth of that proposition. Indecision with regard to $p$ requires that the subject be, in some minimal sense at least, concerned about $p$ 's truth but has not yet formed any settled doxastic attitude with respect to $p$.

With this notion of indecision it is left open why the subject has not formed a doxastic attitude yet. Given that indecision requires cognitive contact, it can be ascribed to subjects at various stages of a deliberation process regarding the truth of some proposition: the doxastic state of indecision seems to be the default state of a subject who starts deliberating about the truth of a proposition which she entertains in thought for the first time. Further, a subject who is in the middle of accumulating evidence but has not reached a verdict yet can be described as doxastically undecided or in the state of pre-decision or mid-wondering. Next, the doxastic state of indecision is a natural fallback position for subjects who gave up their belief, disbelief, or agnosticism because of undercutting defeaters that undermined their respective doxastic stance. Even if these stages of inquiry differ in the subject being more or less informed, they are all uncommitted stages and hence qualify for nonagnostic or 'mere' indecision.

My account of agnosticism as endorsed indecision may appear, at first glance, very close to the meta-cognitive idea that a second-order belief about one's deficient evidential situation is the crucial agnostic element. It is important to note, however, that the role of a subject's indecision within my account of agnosticism is very different from that within other accounts insofar as I do not take indecision to be the result of something subjects do, such as forming the attitude of 'being agnostic'. Rather, I argue that agnostic subjects committed to the indecision they already 
exhibited. Even if I am aware of my own indecision by judging my evidential situation to be insufficient, I am not necessarily agnostic. As I explained in previous sections, the agnostic subject assessed the fact that she is undecided and thereby closed inquiry. A further step is needed for this (admittedly reflective) undecided subject to become agnostic. This further step is the formation of the endorsement attitude which is not a doxastic but rather an evaluative attitude. In the next section, I will explain this attitude of endorsement and the kind of commitment that is involved in settling one's indecision.

\subsection{The attitude of endorsement}

The attitude of endorsement, which I introduced in the beginning of Sect. 3, is meant to be an evaluative attitude by which a subject assesses and approves of the fact that she is in a certain doxastic state regarding $p .^{22}$ I take endorsing to be an inquiry-closing attitude: a subject endorses her indecision if and only if the evaluation is such that inquiry into the truth of $p$ is stopped. By endorsing one's indecision the subject, in some sense at least, identifies with (or commits to) her being in the state of indecision and brings inquiry to an end. This explains why agnosticism is a settled or calm state of mind, and it is in accordance with the traditional interpretation of the 'a-gnostic' being a person who does not know, but who reflected on this fact and is content with this situation.

The attitude of endorsement is directed at one's own de facto doxastic state of indecision: endorsing one's indecision is taking it to be appropriate to neither believe nor disbelieve that $p$ is true such that inquiry into $p$ 's truth is stopped. Note that the endorsement attitude is not in itself an attitude that represents agnosticism or any form of indecision. Subjects can endorse different doxastic states they are in: a subject can also assess her beliefs from a meta-perspective and endorse them accordingly. Endorsing one's de facto belief is taking it to be appropriate to believe that $p .{ }^{23}$ However, only if $S$ endorses her de facto indecision regarding $p$ and stops inquiry into $p$, will this endorsement be constitutive for the complex phenomenon of agnosticism with regard to $p$. Not only the formation of the attitude of endorsement is constitutive of agnosticism, but also the special object of the attitude.

To endorse one's own indecision with respect to $p$, it is required that subjects know or be aware of their indecision with regard to $p$. Usually, people express indecision by saying or thinking 'I don't know', 'I can't say', 'I'm stuck', or 'I can't figure it out'. Non-agnostic indecision may be silent and may go unnoticed, but often people are painfully aware that they are undecided, especially when it matters to them to find the answer to a nagging question but they don't have the means to resolve the issue. Experiencing this mental unease is one way of finding out about one's own (unwelcome) indecision. Knowing about one's own indecision may be

\footnotetext{
${ }^{22}$ Let me note that my usage of endorsement differs in many respects from Fleisher's (2018) who takes it to be a doxastic propositional attitude that shapes and guides an agent's research and inquiry.

23 Arguably, the attitude of endorsement could be defined in more general terms to capture the assessment of non-doxastic states from a meta-perspective. This, however, would also require a redefinition of the kind of commitment that comes with it.
} 
necessary for agnosticism, but it is not sufficient: $S$ may be aware of her indecision about some issue but may go on deliberating about it without ever committing to that indecision of hers. To commit to indecision, $S$ has to do something with this knowledge (or meta-belief) about her own indecision. I want to suggest that this last step to agnosticism, which may (but does not have to be) motivated by the aforementioned meta-belief, is the formation of the attitude of endorsement with respect to one's indecision. By endorsing her indecision, $S$ settles or commits to her indecision regarding $p$ for a reason. She stops deliberating whether $p$ is true and takes a stance without thereby answering the question whether $p$.

The settling of the indecision is separable from the indecision itself because the indecision is not a causal-explanatory result of the formation of the endorsement attitude but rather its object. By forming the endorsement attitude with respect to her indecision, $S$ does not bring about her indecision but only commits to the fact that she is undecided such that inquiry is closed. This structural relation of indecision and its endorsement allows for a smooth transition from mere indecision to agnosticism (Commitment) and back again (Revision). As in Marta's case, subjects can take back their commitment to indecision when they learn that they have been mistaken or that the evidential situation has changed. In cases like Marta's, the subject's doxastic stance is unsettled and falls back to mere or unqualified indecision. Undercutting defeaters do the same with respect to unsettling a subject in her beliefs: $S$ drops the belief that $p$ is true without thereby believing $p$ to be false. The natural fallback position for responding to undercutting defeaters is indecision.

The suggested separation of a subject's indecision and the commitment to her indecision further offers a plausible explanation of how non-epistemic reasons may motivate a subject's agnosticism and why this does not necessarily render agnosticism a non-doxastic state. It seems plausible that, sometimes, subjects suspend for pragmatic reasons, for example, when it is too difficult, risky, or time consuming to find appropriate evidence that determines whether or not $p$ is true. This is not to say that people can suspend at will no matter what the evidence looks like. Because I analyse suspension as endorsed indecision, the subject has to be in the state of indecision regarding the issue in question to be able to endorse this de facto state of hers in the first place. To put it more simply, a subject cannot endorse her state of indecision if she is not in that state. Yet, even if $S$ cannot be undecided for pragmatic reasons, $S$ can endorse her indecision for pragmatic reasons, for example, when $S$ expects further inquiry to be too costly and not productive. These cases have to be distinguished from cases of self-deceit, deliberate ignorance, and blind refusal to inquire. In this paper, however, I will not pursue this topic further. ${ }^{24}$

In contrast to a sui generis attitude, which is merely defined to represent the subject's indecision as well as the commitment without any further structure regarding their relation, a two-component analysis has the required structure to explain what is going on when a subject enters the state of agnosticism by suspending inquiry. Agnosticism can be distinguished from mere indecision without assuming that there are psychologically different kinds of being undecided

${ }^{24}$ I said more on this in Wagner (forthcoming). 
regarding the truth of a proposition. Further, my account adds the required step that allows the use of a meta-belief about one's evidential situation as a reason to suspend. This is the step that is essentially lacking in pure meta-cognitive accounts.

\subsection{Normative profile of endorsed indecision}

Let me briefly point at some implications of my account for the rational profile of agnosticism. ${ }^{25}$ Given the two components of agnosticism I described above, there are two points of reference for its rationality: one concerns the rationality of indecision simpliciter and the other concerns the rational endorsement of that indecision. How do the two interact with one another?

The rationality of indecision simpliciter is clearly epistemic. It is rational for $S$ to be undecided regarding the truth of $p$ if $S$ has no or insufficient evidence because it is impermissible for $S$ to believe or disbelieve a proposition against the evidence or on insufficient grounds. Further, it is rational to be undecided if one's total body of evidence is equally balanced because it is impermissible to believe or disbelieve in the presence of defeaters. One might also think of a subject as irrationally undecided regarding $p$ 's truth if she intentionally avoids reviewing available facts that are potentially relevant for a decision regarding $p$ 's truth.

There are a lot of questions concerning the rationality of endorsing one's indecision. Is it permissible to just endorse one's de facto indecision as it is and not check on it against the body of evidence there is or there could be? In any case, it seems reasonable to endorse one's indecision as appropriate and end inquiry if one judges that one considered all the evidence there is and is still unable to decide the issue. However, as I said before, I think that the subject can commit to indecision for pragmatic considerations, too, and I think that, pragmatically, this is often rationally permissible. ${ }^{26}$ Even if that would mean that the endorsement attitude itself is not a doxastic attitude, the resulting state of agnosticism, which requires that the subject be doxastically undecided, still is. Further, there are rationality constraints with respect to the transition from agnosticism to belief: as I briefly mentioned in the context of Revision, it is impermissible for a subject to stick to her past commitment to indecision if she is not undecided any more. By adopting a belief that $p$ is true, she is rationally obliged to retract her commitment to her past indecision. In Sect. 2.2.3, I gave an example of a subject who violates this obligation by sticking to her past commitment to her former indecision regarding $p$ despite now having adopted the (in this case painful) belief that $p$ is true.

Clearly, a subject is permitted to endorse her indecision only if she is undecided about $p$, but it might be superfluous to require a subject not to be doing something that seems impossible anyway. It is an interesting question, though, whether there are epistemic circumstances that could possibly obligate a subject to endorse her indecision and enter the agnostic state. I have my doubts that there are purely epistemic obligations for being agnostic that come on top of being doxastically

\footnotetext{
25 I want to thank an anonymous reviewer for making this suggestion.

26 In Wagner (forthcoming), I say more about pragmatic reasons for suspension.
} 
neutral in the sense of 'mere' indecision. This, however, is not the place to pursue these questions further.

\subsection{Testing the requirements}

I will quickly go through the requirements I spelt out in the first part to show that my account is able to meet them all.

Cognitive Contact My account of settled indecision makes sure that $S$ cannot be agnostic toward a proposition $p$ if she is not (and never was) cognitively considering $p$ 's truth because the mental state of indecision is defined as the state of non-belief plus cognitive contact (see Sect. 3.1).

Proper End My account of settled indecision is able to explain the difference between subjects who close deliberation by suspending and those who either drop out prematurely or close deliberation in some other way than by suspending. The latter two cases would be such that the subject will not have ended deliberation by endorsing her own indecision. The approval of her own indecision that comes with the endorsement marks the proper end of a deliberation process that moves the subject into the state of agnosticism. Subjects may do all kinds of things to end deliberation (intentionally or not), but only the evaluation of one's indecision as the appropriate doxastic response ends it in the proper way that leads to agnosticism.

Lost Reasons Because the attitude of endorsement is a standing attitude, which can be separated from the reasons for which it was formed, my account meets this requirement. A subject can endorse her own indecision, for example for the reason that the prospect of decisive future evidence is rather dim, and then remain in that state of agnosticism even if, one day, her reason is defeated or she forgets about it.

Doxastic Neutrality Indecision is captured in my account by two necessary conditions that are jointly sufficient: $S$ neither believes nor disbelieves that $p$ and $S$ is or was in cognitive contact with $p$. The agnostic subject is doxastically neutral regarding $p$ 's truth in the same way as the merely undecided subject is. The difference between the two is not the kind of indecision or how it has been brought about; they differ with respect to their present or absent assessment of their de facto indecision.

Commitment My interpretation of "attitudinal commitment to indecision" is as follows: $S$ commits to her de facto indecision by evaluating it as appropriate and thereby stops inquiry. This means that the indecision is the object of the endorsement attitude but not its causal result. The commitment does not bring about or explain the indecision itself, but only qualifies it as appropriate such that inquiry is stopped. A subject who commits to indecision by endorsing it identifies with her own indecision and adopts her indecision as her own. Committing to indecision in this way is the relevant step toward a settled agnostic state that the merely undecided subject does not take.

Revision My account of agnosticism is able to explain the transition from being agnostic to other doxastic states (including non-agnostic indecision) prompted by different kinds of defeaters because it has two independent components that are only structurally related. Whereas rebutting defeaters prompt the (rational) subject to revise the component of indecision (e.g. by adopting a belief), undercutting 
defeaters will only be able to unsettle the agnostic's commitment to indecision but not her indecision as such. My two-component analysis can capture and explain Marta's change of mind from agnosticism to mere indecision, because the indecision-representing aspect of agnosticism is not constituted by the special qualification that comes with the endorsement attitude. Marta can give up the endorsement of her indecision without giving up her indecision altogether.

\section{Conclusion}

In this paper, I attempted to spell out a descriptive account of agnosticism that accommodates the intuitive view that a subject moves into the state of agnosticism by an act (we call suspension) that terminates deliberation in the right way. I started with discussing three requirements for an appropriate account of agnosticism (Cognitive Contact, Proper End, Lost Reasons) that I dedicated to Jane Friedman (2013b), who convincingly argued that it is the formation of an attitude that is best suited to capturing this transition from an undecided deliberative state to the state of agnosticism. I then introduced three further requirements (Doxastic Neutrality, Commitment, Revision) on the basis of which I compared meta-cognitive accounts and sui generis attitude accounts of agnosticism. Even though the two rivalling accounts have different problems in accommodating these requirements, the problems stem from the same source: both accounts analyse the agnostic's commitment to indecision as a commitment that brings about the indecision as its result.

In my own account, I addressed the indecision and the commitment to indecision as independent components that are only structurally related. A subject who commits to indecision endorses the fact that she is undecided with regard to that issue. I take the act of suspension to be the formation of the endorsement attitude with respect to one's own indecision. This evaluation of one's own indecision as the appropriate doxastic response brings deliberation to an end. Let me close with the metaphor I brought up in the introduction: in some sense, the suggested settled form of indecision works like two-component glue. Because the hardener and the resin are packed in separate cartridges, the hardener does not bring about the resin, but if the two are mixed together appropriately, the resin's chemical structure is stabilised via a chemical reaction. Likewise, the subject's commitment to her own indecision does not bring about that she is undecided but only stabilises, or settles, her de facto indecision. Unfortunately, the glue metaphor is not perfect because the chemical reaction is irreversible. This is not the case for one's commitment to indecision. Agnosticism can be revised by adopting a belief but also by giving up the endorsement of one's indecision. If a subject's agnosticism is unsettled by undercutting defeaters, she can take back the commitment of her indecision without thereby giving up her indecision altogether.

Acknowledgements This paper profited from discussions with audiences in Konstanz, Düsseldorf, Dresden, Köln, Mannheim, Saarbrücken and Stuttgart. I am indebted to Thomas Müller for supporting me in this project and to Daniela Schuster who never got tired of reading new (and newer) versions of this 
paper. I am grateful to Christopher von Bülow for proofreading. My special thanks go to two anonymous reviewers who provided me with insightful comments and constructive feedback that helped to improve this paper significantly. I thank the Baden-Württemberg Stiftung for financially supporting this research project.

Funding Open Access funding enabled and organized by Projekt DEAL.

Open Access This article is licensed under a Creative Commons Attribution 4.0 International License, which permits use, sharing, adaptation, distribution and reproduction in any medium or format, as long as you give appropriate credit to the original author(s) and the source, provide a link to the Creative Commons licence, and indicate if changes were made. The images or other third party material in this article are included in the article's Creative Commons licence, unless indicated otherwise in a credit line to the material. If material is not included in the article's Creative Commons licence and your intended use is not permitted by statutory regulation or exceeds the permitted use, you will need to obtain permission directly from the copyright holder. To view a copy of this licence, visit http:// creativecommons.org/licenses/by/4.0/.

\section{References}

Anderson, C. (1995). Implicit personality theories and empirical data: Biased assimilation, belief perseverance and change, and covariation detection sensitivity. Social Cognition, 13(1), $25-48$.

Anglin, S. (2019). Do beliefs yield to evidence? Examining belief perseverance vs. change in response to congruent empirical findings. Journal of Experimental Social Psychology, 82, 176-199.

Archer, A. (2018). Wondering about what you know. Analysis, 78(4), 596-604.

Archer, A. (2019). Agnosticism, inquiry, and unanswerable questions. Disputatio, 11(53), 63-88.

Atkinson, C. J. (2021). The aim of belief and suspended belief. Philosophical Psychology, 34(4), 581-606.

Bergmann, M. (2005). Defeaters and higher-level requirements. The Philosophical Quarterly, 55(220), 419-436.

Crawford, S. (2004). A solution for Russellians to a puzzle about belief. Analysis, 64(3), 223-229.

Fleisher, W. (2018). Rational endorsement. Philosophical Studies, 175(10), 2649-2675.

Friedman, J. (2013a). Question-directed attitudes. Philosophical Perspectives, 27(1), 145-174.

Friedman, J. (2013b). Suspended judgment. Philosophical Studies, 162(2), 165-181.

Friedman, J. (2017). Why suspend judging? Noûs, 51(2), 302-326.

Friedman, J. (2019). Inquiry and belief. Nô̂s, 53(2), 296-315.

Hájek, A. (1998). Agnosticism meets Bayesianism. Analysis, 58(3), 199-206.

Lord, E. (2020). Suspension of judgment, rationality's competition, and the reach of the epistemic. In S. Schmidt \& G. Ernst (Eds.), The Ethics of Belief and Beyond. Understanding Mental Normativity (pp. 126-145). Routledge.

Lord, E., \& Sylvan, K. (forthcoming). Suspension, higher-order evidence, and defeat. In M. Simion \& J. Brown (Eds.), Reasons, Justification, and Defeat. Oxford University Press.

Masny, M. (2020). Friedman on suspended judgment. Synthese, 197, 5009-5026.

McGrath, M. (2021). Being neutral: Agnosticism, inquiry and the suspension of judgment. Noûs, 55(2), $463-484$.

Nestler, S. (2010). Belief perseverance: The role of accessible content and accessibility experiences. Social Psychology, 41, 35-41.

Pollock, J. (1987). Defeasible reasoning. Cognitive Science, 11(4), 481-518.

Raleigh, T. (2021). Suspending is believing. Synthese, 198, 2449-2474.

Rosenkranz, S. (2007). Agnosticism as a third stance. Mind, 116, 55-104.

Smart, J. (2020). Disbelief is a distinct doxastic attitude. Synthese. https://doi.org/10.1007/s11229-02002830-w.

Staffel, J. (2019). Credences and suspended judgments as transitional attitudes. Philosophical Issues, 29(1), 281-294. 
Sturgeon, S. (2010). Confidence and coarse-grained attitudes. In T. Gendler \& J. Hawthorne (Eds.), Oxford Studies in Epistemology (Vol. 3, pp. 126-149). Oxford University Press.

Sylvan, K. (2016). The illusion of discretion. Synthese, 193(6), 1635-1665.

Wagner, V. (forthcoming). Epistemic dilemma and epistemic conflict. In: K. McCain, S. Stapleford \& M. Steup (Eds.), Epistemic Dilemmas: New Arguments, New Angles. Routledge.

Wedgwood, R. (2002). The aim of belief. Philosophical Perspectives, 16, 267-297.

Publisher's Note Springer Nature remains neutral with regard to jurisdictional claims in published maps and institutional affiliations. 